\title{
The Development and Application of Crop Evaluation System Based on GRA
}

\author{
Ruihong Wang, ${ }^{1}$ Liguo Zhang, ${ }^{1}$ Lianjie Dong, ${ }^{2}$ and Xiuying $\mathrm{Lu}^{3}$ \\ ${ }^{1}$ College of Information Science \& Technology, Agricultural University of Hebei, Baoding, China \\ ${ }^{2}$ College of Science, Agricultural University of Hebei, Baoding, China \\ ${ }^{3}$ Agricultural University of Hebei, Baoding, China \\ Correspondence should be addressed to Ruihong Wang; xxwrh@hebau.edu.cn
}

Received 16 June 2016; Revised 15 October 2016; Accepted 24 October 2016

Academic Editor: Alberto Borboni

Copyright (C) 2016 Ruihong Wang et al. This is an open access article distributed under the Creative Commons Attribution License, which permits unrestricted use, distribution, and reproduction in any medium, provided the original work is properly cited.

\begin{abstract}
Ever since it was proposed, grey system theory has attracted the attention of scientific researchers and scholars. And it also has been widely used in many fields and solved a large number of practical problems in production, life, and scientific research. With the development and popularization of computer science and network technology, this traditional mathematical model can be applied more simply and efficiently to solve practical problems. Firstly, this paper, to implement steps of grey relational analysis, has made the exclusive analysis and has made the simple introduction to grey relational analysis characteristics. Then, based on grey relational theory and ASP.NET technology, the crop evaluation system is developed. Lastly, by using Excel and the crop evaluation system, the paper carries out a comprehensive evaluation about eight features of Fuji apple, which is from nine different producing areas, respectively. The experiment results show that the crop evaluation system is effective and could greatly improve the work efficiency of the researcher and expand the application scope.
\end{abstract}

\section{Introduction}

Grey System. In today's world, society has been in the information age. It contains a large number of known, unknown, and unascertained information. We call it grey system which contains less, incomplete, and uncertain information, proposed by Deng Julong in $1982[1,2]$. Its research mainly includes grey system modeling theory, grey system controlling theory, grey relational analysis (GRA) [3], grey prediction method, grey planning method, and grey decisionmaking method.

Grey system is mainly used to solve the "limited sample, less information" problem [4-6], which cannot be solved by statistics and fuzzy mathematics. On the basis of information coverage, it seeks the practical regular by generating the sequence. Its characteristic is "less data model" [7-10].

Grey Relational Analysis. GRA is not only an important part of grey system but also the cornerstone of analysis, prediction, and decision-making of grey system [11-15].
When we study a system, we should distinguish the main factors and secondary factors, which promote the development of system or hinder that. Because the information is incomplete and uncertain, it is difficult to determine the relationship of all factors and is difficult to distinguish the main factors and secondary factors in the grey system. The main function of the GRA is to quantify and sort those factors, so as to analyze the system.

At first, we calculate the relational coefficient of each program and the ideal program composed by best indicator and then calculate the relational degree from coefficient. Finally, according to the size of relational degree, we sort, analyze, and draw conclusion. This approach is superior to classical exact mathematical methods. This method breaks through constraints of traditional precise mathematics, which does not tolerate ambiguity. It has many significant features, such as far from simple, easy to grasp, simple calculation, clear sort, no special requirements for the data distribution type, and variable type. So it is widely used in many fields [16-23], such as evaluation of citrus quality, breeding selection of wheat 


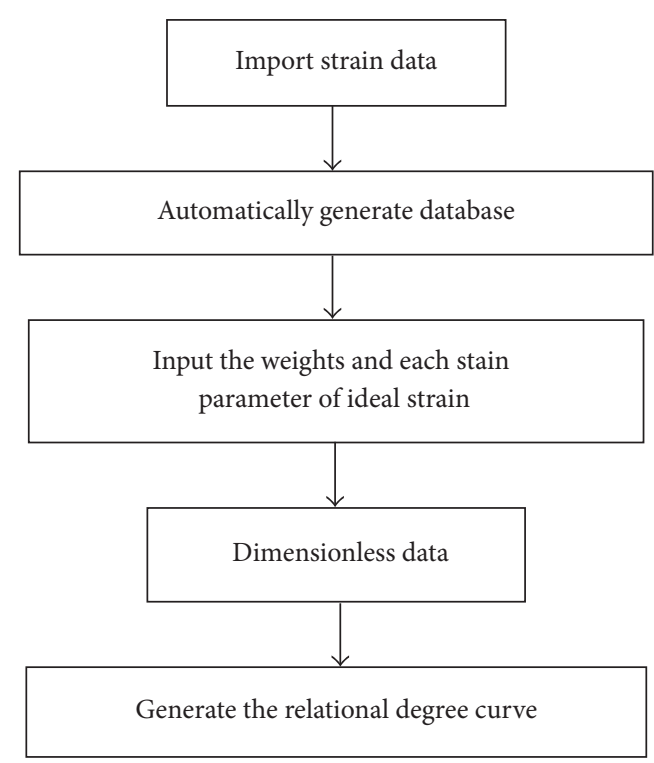

FIGURE 1: Workflow of crop evaluation system.

strain, application of potato new strain, breeding selection of oil-tea, application research of rice new strain, and analysis on yield and main characters of soybean strains.

Grey Relational Degree. The theory tool of GRA is the grey relational degree. It measures the relational degree among factors. If two factors have similar changing trend, the grey relational degree is large. On the other hand, the grey relational degree is small. In turn, we can use the grey relational degree to judge the degree of correlation between factors.

When we analyze abstract system or phenomenon, we firstly select the right sequence data reflecting the characteristic of system behavior, which is called mapping of seeking system behavior. The sequence data is indirectly used to characterize the system behavior. Then we also need to further clarify the effective factors that affect system main behavior. When we make the quantitative analysis, we must transform the system behavior characteristic and each effective factor for similar dimensionless quantitative data and transform negative relational factor for a positive relational factor.

Since Professor Deng Julong proposed the system in 1982, grey system has rapidly grown and developed, but there is no software development. So we develop crop evaluation system by using C\# program language. The workflow of crop evaluation system is shown in Figure 1. This evaluation system can greatly improve the work efficiency for the researcher and expand the application scope of this method.

\section{Materials and Methods}

Relational degree is a relevance measure between the things and factors. We find it from the random time series, so as to provide evidence for factor analysis and forecasting accuracy analysis. And the relational degree is not only a basis for decision-making but also a method to determine the main factors. Therefore, how to define a reasonable calculation method of relational degree has important significance. Common relational degree definitions are the following: Deng relational degree, absolute relational degree, $\mathrm{T}$ relational degree, B relational degree, and C relational degree. In this paper, we adopt Deng relational degree to carry out the evaluation model.

According to Deng relational degree, when we evaluate the Fuji apple from 9 different producing areas [24], we set its 8 features as a grey system and set each feature as a factor in system. Before evaluation, we firstly set an ideal variety as an evaluation standard.

Set the index of ideal variety, constitute the sequence of reference series $X_{0}$, the rest varieties as test series $X_{i}$, and then generate sequence $X_{0}=\left[X_{0}(1), X_{0}(2), \ldots, X_{0}(n)\right], X_{i}=$ $\left[X_{i}(1), X_{i}(2), \ldots, X_{i}(n)\right] . n$ is the factor number. $i$ denotes $i$ th variant. We can use the following formulas to calculate the relational coefficient, equal-weighted degree, and weighted degree.

Relational coefficient [25-28] is

$$
\begin{aligned}
& \xi_{i}(k) \\
& =\frac{\min \min \left|x_{0}(k)-x_{i}(k)\right|+\rho \max \max \left|x_{0}(k)-x_{i}(k)\right|}{\left|x_{0}(k)-x_{i}(k)\right|+\rho \max \max \left|x_{0}(k)-x_{i}(k)\right|} .
\end{aligned}
$$

Equal-weighted degree is

$$
r_{i}=\frac{1}{n} \sum_{1}^{n} \xi_{i}(k) .
$$

Weighted degree is

$$
r_{i}^{*}=\frac{1}{n} \sum_{1}^{n} \xi_{i}(k) W_{i} .
$$

Here, $\left|X_{0}(K)-X_{i}(K)\right|=\Delta_{i}(K)$ is the absolute difference between $X_{0}$ sequence and $X_{i}$ sequence at $K$ point; $\min _{i} \min _{k}\left|X_{0}(K)-X_{i}(K)\right|$ is secondary minimum difference; $\max _{i} \max _{k}\left|X_{0}(K)-X_{i}(K)\right|$ is the secondary maximum difference; $\rho$ is the distinguishing coefficient, and its value ranges from 0 to 1 , usually taking $0.5 ; \xi_{i}(k)$ is the weighting coefficient. Its size was based on results of previous studies, experience, target selection, and expert appraisal results; $W_{i}$ is weight coefficient of each character. According to $r_{i}$ or $r_{i}^{*}$, the relational degrees of tested varieties are calculated. The bigger the value of tested variety, the more excellent the variety. On the contrary, it is poor.

\section{Results}

3.1. Performance of the Method. In this paper, with the Fuji for example, we introduce the evaluation system process and carry out the evaluation model. We analyze 8 characters of Fuji apple from 9 different producing areas. 8 characters are fruit volume $(\mathrm{mL})$, skin color, flesh color, starch content (\%), the juice yield (\%), solid acid ratio, fruit firmness (g), and protein content $(\mathrm{g} / 100 \mathrm{~g})$. Raw data sheet was shown in Table 1 . 
TABLE 1: Raw data.

\begin{tabular}{|c|c|c|c|c|c|c|c|c|}
\hline \multicolumn{2}{|c|}{ Input the crop name } & \multicolumn{2}{|c|}{ Apple } & \multicolumn{2}{|c|}{ Input characters number } & \multicolumn{3}{|c|}{8} \\
\hline Input the weight & 0.08 & 0.16 & 0.16 & 0.16 & 0.04 & 0.16 & 0.16 & 0.08 \\
\hline Characters' name & uit volume & Skin color & Flesh color & Starch content & The juice yield & Solid acid ratio & Fruit firmness & Protein content \\
\hline Ideal variety & 320.00 & 12.00 & -0.20 & 0.40 & 58.00 & 55.00 & 273.71 & 0.56 \\
\hline 1 & 318.22 & 13.40 & 0.35 & 0.47 & 57.52 & 48.11 & 273.71 & 0.30 \\
\hline 2 & 227.22 & 14.10 & 0.09 & 0.65 & 73.47 & 64.71 & 252.86 & 0.46 \\
\hline 3 & 240.33 & 11.10 & 0.17 & 0.59 & 64.13 & 76.05 & 273.05 & 0.37 \\
\hline 4 & 319.33 & 17.23 & 0.06 & 0.66 & 68.46 & 48.39 & 248.93 & 0.27 \\
\hline 5 & 224.67 & 13.37 & 0.13 & 0.74 & 62.49 & 52.31 & 275.93 & 0.31 \\
\hline 6 & 275.67 & 9.89 & -0.20 & 0.99 & 67.22 & 55.26 & 247.04 & 0.38 \\
\hline 7 & 289.44 & 12.97 & 0.29 & 0.48 & 59.93 & 42.96 & 247.04 & 0.45 \\
\hline 8 & 305.56 & 10.87 & 0.25 & 0.99 & 67.25 & 49.17 & 226.14 & 0.35 \\
\hline 9 & 288.22 & 16.45 & 0.11 & 0.43 & 62.55 & 38.33 & 269.13 & 0.56 \\
\hline
\end{tabular}

TABLE 2: Dimensionless quantity.

\begin{tabular}{lcccccccc}
\hline \multicolumn{2}{l}{ Characters' name Fruit volume } & Skin color & Flesh color & Starch content & The juice yield & Solid acid ratio & Fruit firmness & Protein content \\
\hline Ideal variety & 1.00 & 1.00 & 1.00 & 1.00 & 1.00 & 1.00 & 1.00 \\
\hline 1 & 0.99 & 1.12 & -1.75 & 1.16 & 0.99 & 0.87 & 1.00 & 1.00 \\
2 & 0.71 & 1.18 & -0.44 & 1.61 & 1.27 & 1.18 & 0.92 & 0.53 \\
3 & 0.75 & 0.93 & -0.85 & 1.48 & 1.12 & 1.38 & 1.00 & 0.81 \\
4 & 1.00 & 1.44 & -0.32 & 1.65 & 1.31 & 0.88 & 0.91 & 0.65 \\
5 & 0.70 & 1.11 & -0.65 & 1.84 & 0.83 & 0.95 & 0.47 \\
6 & 0.86 & 0.82 & 1.00 & 2.48 & 0.90 & 1.00 & 0.90 & 0.54 \\
7 & 0.90 & 1.08 & -1.45 & 1.19 & 0.95 & 0.78 & 0.90 & 0.79 \\
8 & 0.95 & 0.91 & -1.25 & 2.48 & 0.74 & 0.89 & 0.83 & 0.62 \\
9 & 0.90 & 1.37 & -0.55 & 1.06 & 0.85 & 0.70 & 0.98 & 0.99 \\
\hline
\end{tabular}

TABLE 3: Absolute difference.

\begin{tabular}{lcccccccc}
\hline Characters' name & $\triangle 1$ & $\triangle 2$ & $\triangle 3$ & $\triangle 4$ & $\triangle 5$ & $\triangle 6$ & $\triangle 7$ & $\triangle 8$ \\
\hline 1.00 & 0.01 & 0.12 & 2.75 & 0.16 & 0.01 & 0.13 & 0.00 & 0.47 \\
2.00 & 0.29 & 0.18 & 1.44 & 0.61 & 0.27 & 0.18 & 0.08 & 0.19 \\
3.00 & 0.25 & 0.08 & 1.85 & 0.48 & 0.12 & 0.38 & 0.00 & 0.35 \\
4.00 & 0.00 & 0.44 & 1.32 & 0.65 & 0.31 & 0.12 & 0.09 & 0.53 \\
5.00 & 0.30 & 0.11 & 1.65 & 0.84 & 0.17 & 0.05 & 0.01 & 0.46 \\
6.00 & 0.14 & 0.18 & 0.00 & 1.48 & 0.10 & 0.00 & 0.10 & 0.33 \\
7.00 & 0.10 & 0.08 & 2.45 & 0.19 & 0.05 & 0.22 & 0.10 & 0.21 \\
8.00 & 0.05 & 0.09 & 2.25 & 1.48 & 0.26 & 0.11 & 0.17 & 0.38 \\
9.00 & 0.10 & 0.37 & 1.55 & 0.06 & 0.15 & 0.30 & 0.02 & 0.01 \\
\hline
\end{tabular}

First, nondimensional treatment for the original data is done. According formula (4), calculate the nondimensional data as shown in Table 2.

$$
L h(k)=\frac{X_{i}(k)}{X_{0}(k)} .
$$

Here, $L h(k)$ denotes $k$ th character of $i$ th variant.

Second, according to the dimensionless quantity sheet and formula (5), calculate each relevant absolute difference
TABLE 4: Correlative coefficients.

\begin{tabular}{|c|c|c|c|c|c|c|c|c|}
\hline Characters' name & 1.00 & 2.00 & 3.00 & 4.00 & 5.00 & 6.00 & 7.00 & 8.00 \\
\hline 1 & 1.00 & 0.92 & 0.33 & 0.89 & 0.99 & 0.92 & 1.00 & 0.74 \\
\hline 2 & 0.83 & 0.89 & 0.49 & 0.69 & 0.84 & 0.89 & 0.95 & 0.88 \\
\hline 3 & 0.85 & 0.95 & 0.43 & 0.74 & 0.92 & 0.78 & 1.00 & 0.80 \\
\hline 4 & 1.00 & 0.76 & 0.51 & 0.68 & 0.82 & 0.92 & 0.94 & 0.72 \\
\hline 5 & 0.82 & 0.92 & 0.45 & 0.62 & 0.89 & 0.97 & 0.99 & 0.75 \\
\hline 6 & 0.91 & 0.89 & 1.00 & 0.48 & 0.93 & 1.00 & 0.93 & 0.81 \\
\hline 7 & 0.94 & 0.94 & 0.36 & 0.88 & 0.97 & 0.86 & 0.93 & 0.87 \\
\hline 8 & 0.97 & 0.94 & 0.38 & 0.48 & 0.84 & 0.93 & 0.89 & 0.78 \\
\hline 9 & 0.93 & 0.79 & 0.47 & 0.96 & 0.90 & 0.82 & 0.99 & 0.99 \\
\hline
\end{tabular}

between reference sequence and comparative sequence and get absolute difference as shown in Table 3.

$$
\Delta_{i}(K)=\left|X_{0}(K)-X_{i}(K)\right|
$$

Third, according to the relational coefficients sheet using formula (1), get correlative coefficients as shown in Table 4.

Inputting the weight in the raw data sheet, using correlative coefficients and formula (3), we calculate weighted relational degree of the Fuji apple quality from different origin and get weighted relational degree as shown in Table 5.

Using the chart function in Excel 2003, we generate the clumps bar graph as shown in Figure 2. 
TABLE 5: Relational degree.

\begin{tabular}{lcc}
\hline Characters' name & Relational degree & Sort \\
\hline 1.00 & 0.83 & 3.00 \\
2.00 & 0.79 & 6.00 \\
3.00 & 0.79 & 7.00 \\
4.00 & 0.78 & 8.00 \\
5.00 & 0.80 & 5.00 \\
6.00 & 0.86 & 1.00 \\
7.00 & 0.82 & 4.00 \\
8.00 & 0.75 & 9.00 \\
9.00 & 0.83 & 2.00 \\
\hline
\end{tabular}

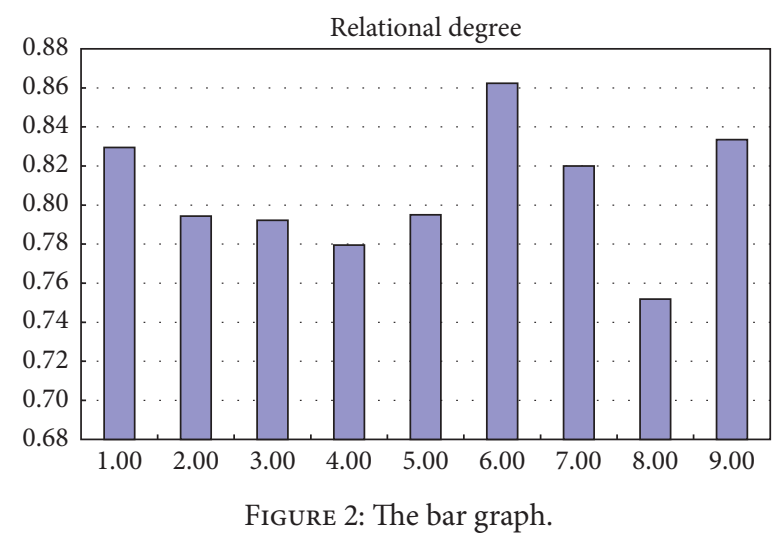

If we input equal-weight in the raw data sheet (as shown in Table 6), then final equal-weighted relational degree clumps bar graph is generated as shown in Figure 3.

According to relational analysis principle, the sequence, in which relational degree is biggest, is most close to reference sequence; that is, the variety is more close to "ideal variety." Among them, 9th variety is most close to "ideal variety," followed by 6 th variety. 8 th variety has max difference with it, indicating that its comprehensive quality is worst. The rest of origin Fuji apple is centered. The weighted relational degree has the same sort as the equal-weight, mainly due to the same importance of quality indexes.

3.2. Crop Evaluation System. In the above section, we have established the evaluation model. It can be seen that the whole process is very cumbersome and complex. In particular for the less skilled computer user, the biggest drawback is that $[29,30]$ when the objects change, performance indicators may be different and the weight of each index may need to be changed and then the user will not be able to simply and flexibly use the model. In order to make the model become more widely used, easily increase or decrease characteristic number, and modify the characteristics weight, we use C\# program language to develop the software based on the above model and analysis steps. It achieves automatic calculation and analysis of data. The software interface and operation is as follows:
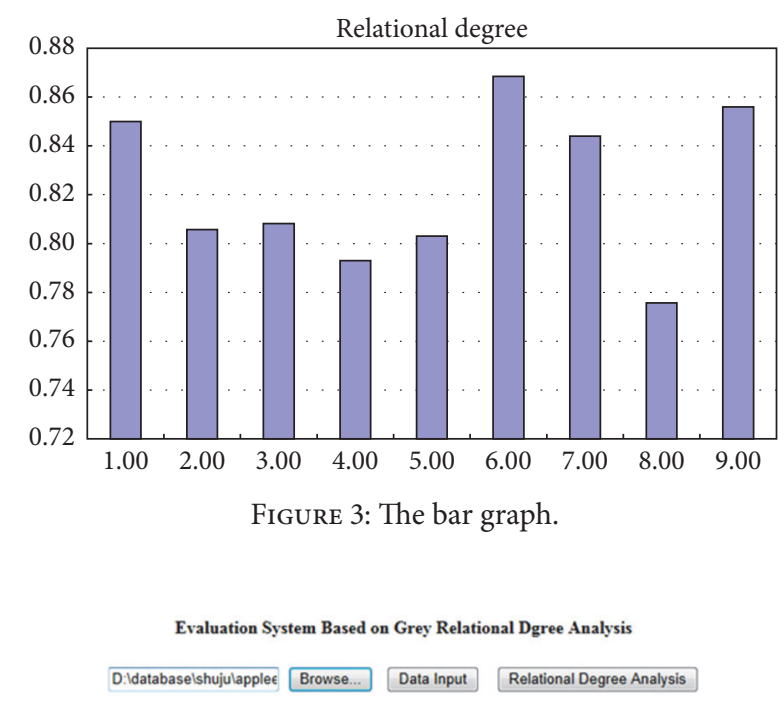

FIGURE 4: Main interface.

(1) Operating system is the main interface as shown in Figure 4.

(2) First, import each strain of data to be analyzed; the data is written in Excel format. The data format is as shown in Figure 5.

(3) Browse the file and find the data sheet to be analyzed and then click the button "data import" to import the data. The software automatically calculates the number of strains and indicators. Interface is shown in Figure 6.

(4) According the user requirement, the operator inputs the weight and each trait parameter of ideal strain; then click the button "relational degree analysis" and the software generates the relational degree curve. This paper adopts the same data as introduced in Excel methods in Figure 5. The result was shown in Figure 7.

\section{Discussion}

GRA method is one of the very popular methods to analyze various relationships among the discrete data sets. The major advantages of the GRA method are that the results are based on the original data and the calculations are simple and straightforward. Different from previous studies, the paper established the crop evaluation model based on the basic ideal of traditional grey relational analysis (GRA) method and, also, developed the crop evaluation system based on the model. With friendly interface and being easy to operate, the software can be easily performed on computer and suitable for different families, genera, and species of plants. The disadvantages of the traditional grey correlation analysis are overcome. In addition, setting weights is the key step of crop evaluation; the operator can give different weights according to different crop types in the evaluation system. 
TABLE 6: Equal-weight.

\begin{tabular}{lcccccccc}
\hline \multicolumn{2}{l}{ Input the crop name } & \multicolumn{2}{c}{ Apple } & \multicolumn{2}{c}{ Input characters number } \\
\hline Input the weight & 0.125 & 0.125 & 0.125 & 0.125 & 0.125 & 0.125 & 0.125 & 0.125 \\
\hline \multicolumn{2}{l}{ Characters' name Fruit volume } & Skin color & Flesh color & Starch content & The juice yield & Solid acid ratio & Fruit firmness & Protein content \\
\hline Ideal variety & 320.00 & 12.00 & -0.20 & 0.40 & 58.00 & 55.00 & 273.71 & 0.56 \\
\hline 1 & 318.22 & 13.40 & 0.35 & 0.47 & 57.52 & 48.11 & 273.71 & 0.30 \\
2 & 227.22 & 14.10 & 0.09 & 0.65 & 73.47 & 64.71 & 252.86 & 0.46 \\
3 & 240.33 & 11.10 & 0.17 & 0.59 & 64.13 & 76.05 & 273.05 & 0.37 \\
4 & 319.33 & 17.23 & 0.06 & 0.66 & 68.46 & 48.39 & 248.93 & 0.27 \\
5 & 224.67 & 13.37 & 0.13 & 0.74 & 62.49 & 52.31 & 275.93 & 0.31 \\
6 & 275.67 & 9.89 & -0.20 & 0.99 & 67.22 & 55.26 & 247.04 & 0.38 \\
7 & 289.44 & 12.97 & 0.29 & 0.48 & 59.93 & 42.96 & 247.04 & 0.45 \\
9 & 305.56 & 10.87 & 0.25 & 0.99 & 67.25 & 49.17 & 226.14 & 0.35 \\
9
\end{tabular}

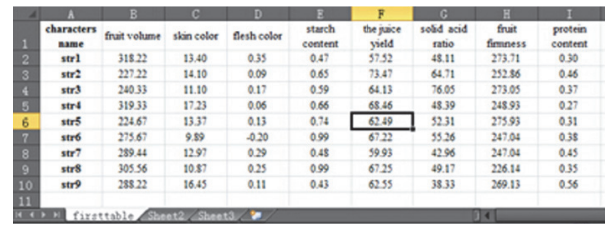

FIgURE 5: The data format.

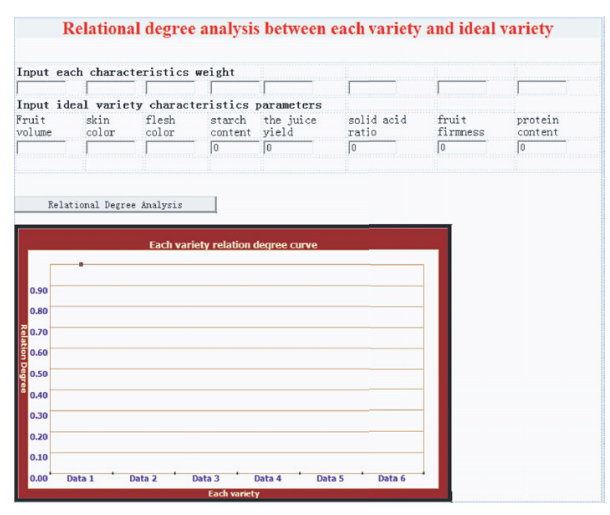

FIGURE 6: The operation interface.

\section{Conclusions}

GRA is part of grey system theory, which is suitable for solving complicated interrelationships between multiple factors and variables. When used to evaluate different crops quality, it can make full use of all the information about fruit quality traits and can give an objective and reasonable sort. As discussed in the above sections, traditional methods have many shortcomings: using weighted relational degree to evaluate different crops quality the distribution of weight often needs to be changed. The interface is not friendly. The operation is not convenient and calculation process is complex and so on. The developed crop evaluation system overcomes the above shortcomings. Taking the Fuji data as experimental data, the paper made the relational degree analysis. It shows that the developed crop evaluation system can greatly improve the

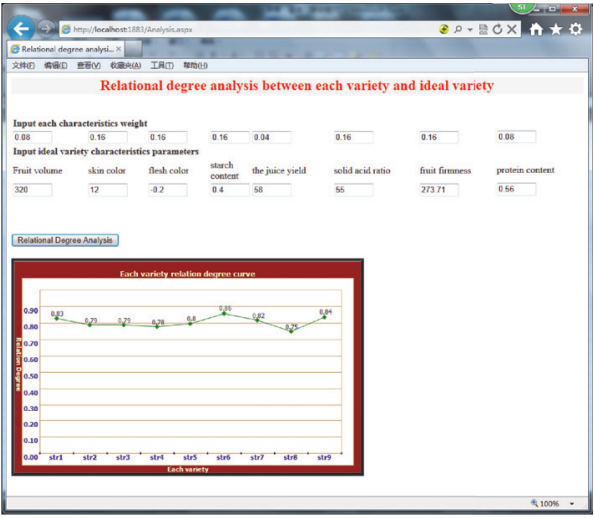

Figure 7: Relational degree curve.

work efficiency of the researcher and expand the application scope.

\section{Competing Interests}

The authors declare that they have no competing interests.

\section{Acknowledgments}

This work was supported by Science and Technology Plan Projects of Hebei province (nos. 15210138 and 15ZN010).

\section{References}

[1] L. Weizhong, A. Yinghui, X. Chongxiang et al., "Phenotypic character and yield research of maizi inbred lines based on GRA," Crops, vol. 5, pp. 105-108, 2012.

[2] W. Ma, Q. Guo, C. Wei, H. Li, C. Peng, and Z. Liang, "Comprehensive evaluation of new self-cultivated sugarcane lines by grey relational analysis," Asian Agricultural Research, vol. 6, no. 9, pp. 85-88, 2014.

[3] X.-F. Yan and Y. Shen, "Comprehensive quality evaluation of dehaired cashmere fiber based on grey relational analysis," Wool Textile Journal, vol. 42, no. 11, pp. 46-50, 2014. 
[4] Z. Qifen and C. Ruyi, "Influence factors analysis of housing demand by grey theory system," China Collective Economy, vol. 10, no. 28, pp. 77-78, 2014.

[5] L. Pei and Z. Jian, "Grey relational analysis of producer services based on panal data," Economic Research Guide, no. 28, pp. 51$52,2014$.

[6] Y. Kuo, T. Yang, and G.-W. Huang, “The use of grey relational analysis in solving multiple attribute decision-making problems," Computers and Industrial Engineering, vol. 55, no. 1, pp. 80-93, 2008.

[7] S.-Q. Jiang, S.-F. Liu, Z.-X. Liu, and Z.-G. Fang, "Grey incidence decision making model based on area," Control and Decision, vol. 30, no. 4, pp. 685-690, 2015.

[8] Y. Li and X. Zhang, "Application of grey relational analysis based on entropy-weight in the assessment of urban sustainable development," Journal of University of Chinese Academy of Science, vol. 31, no. 5, pp. 662-670, 2014.

[9] J.-S. Heh, "Evaluation model of problem solving," Mathematical and Computer Modelling, vol. 30, no. 11-12, pp. 197-211, 1999.

[10] W.-C. Chang, K.-L. Wen, H. S. Chen, and T.-C. Chang, "Selection model of pavement material via Grey relational grade," in Proceedings of the IEEE International Conference on Systems, Man and Cybernetics, pp. 3388-3391, October 2000.

[11] Z. Xianliang, W. Zhanqing, H. Zhibang et al., "Grey correlation multidimensional comprehensive evaluation of new watermelon varieties," Journal of Shanxi Agricultural Sciences, vol. 42, no. 10, pp. 1067-1070, 2014.

[12] G. Fenglian, W. Qiang, and L. Peipei, "Application of grey correlation degree of evaluation of different organic fertilizer rotten proportion," Journal of Anhui Agricultural Sciences, vol. 42, no. 29, pp. 10054-10056, 2014.

[13] G.-W. Wei, "GRA method for multiple attribute decision making with incomplete weight information in intuitionistic fuzzy setting," Knowledge-Based Systems, vol. 23, no. 3, pp. 243-247, 2010.

[14] P. N. Singh, K. Raghukandan, and B. C. Pai, "Optimization by Grey relational analysis of EDM parameters on machining Al10\% SiCP composites," Journal of Materials Processing Technology, vol. 155-156, no. 1-3, pp. 1658-1661, 2004.

[15] J. Hou, "Grey relational analysis method for multiple attribute decision making in intuitionistic fuzzy setting," Journal of Convergence Information Technology, vol. 5, no. 10, pp. 194-199, 2010.

[16] A. Borboni and R. Faglia, "Stochastic evaluation and analysis of free vibrations in simply supported piezoelectric bimorphs," Journal of Applied Mechanics, Transactions ASME, vol. 80, no. 2, Article ID 021003, 2013.

[17] Q. Song and A. Jamalipour, "Network selection in an integrated wireless lan and UMTS environment using mathematical modeling and computing techniques," IEEE Wireless Communications, vol. 12, no. 3, pp. 42-48, 2005.

[18] J. Shen, S. Shi, Y. Zhou, Y. Zhang, and Z. Yao, "Surface water environmental quality assessment of danjiangkou valley based on improved grey correlation analysis," Environmental Monitoring in China, vol. 5, no. 10, pp. 41-46, 2014.

[19] Z. Gu, H. Chen, Y. Wang, Y. Sun, J. Ding, and Y. Zhang, "Safety evaluation of angelicae sinensis radix by grey incidence degree method," Chinese Journal of Experimental Traditional Medical Formulae, vol. 17, no. 9, pp. 60-64, 2014.

[20] A. Tao and H. Yin, "An analysis on the energy consumption and economy increase based on grey relation theory," in Proceedings of the International Conference on Engineering and Business Management (EBM '11), 2011.

[21] J. Zhao and X. Wang, "The grey relational analysis of $\mathrm{CO}_{2}$ emissions and its influencing factors," in Proceedings of the IEEE International Conference on Engineering Technology and Economic Management (ICETEM '12), Beijing, China, 2012.

[22] G. Li, H.-J. Han, and X.-M. Huang, "Gray relational evaluation model with weights based on DEA cross-efficiency," in Proceedings of the 2nd International Conference on Industrial Mechatronics and Automation (ICIMA '10), pp. 236-239, May 2010.

[23] Y. Lu and H. Wei, "Research on the motivation of the customer participation based on gray relational analysis," in Proceedings of the International Conference on Business Management and Electronic Information (BMEI '11), vol. 3, pp. 438-441, May 2011.

[24] W. Xuan, B. Jinfeng, L. Xuan et al., "Grey application of grey correlation analysis for evaluating the overall quality of fuji apples from different growing areas," Food Science, vol. 34, no. 23, pp. 88-91, 2013.

[25] H. Zhang, T. Han, and J. Liu, "Evaluation of peach quality based on grey relational analysis," Northern Horticulture, no. 12, pp. 9$13,2008$.

[26] W. Xiuping, Z. Guoxin, L. Xuelin et al., "Comprehensive evaluation of rice new variety based on grey relational analysis," Chinese Agricultural Science Bulletin, vol. 22, no. 8, pp. 557-559, 2006.

[27] C.-K. Ke and M.-Y. Wu, "A selection approach for optimized problem-solving process by grey relational utility model and multicriteria decision analysis," Mathematical Problems in Engineering, vol. 2012, Article ID 293137, 14 pages, 2012.

[28] S. Ghosh, P. Sahoo, and G. Sutradhar, "Tribological performance optimization of $\mathrm{Al}-7.5 \% \mathrm{SiCp}$ composites using the taguchi method and grey relational analysis," Journal of Composites, vol. 2013, Article ID 274527, 9 pages, 2013.

[29] C. Lingguang, "Application of grey relational analysis in oil-tea breeding," Forest Inventory and Planning, vol. 34, no. 4, pp. 3336, 2009.

[30] Z. Shaorong and L. Guo, "Comprehensive evaluation of potato new variety by grey relational analysis," Journal of Mountain Agriculture and Biology, vol. 23, no. 3, pp. 202-205, 2004. 


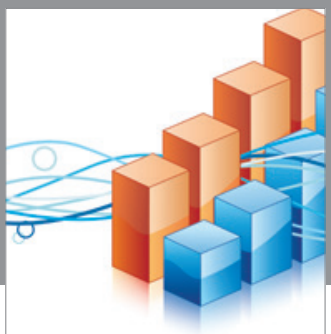

Advances in

Operations Research

vatem alat4

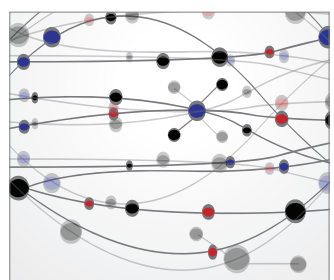

\section{The Scientific} World Journal
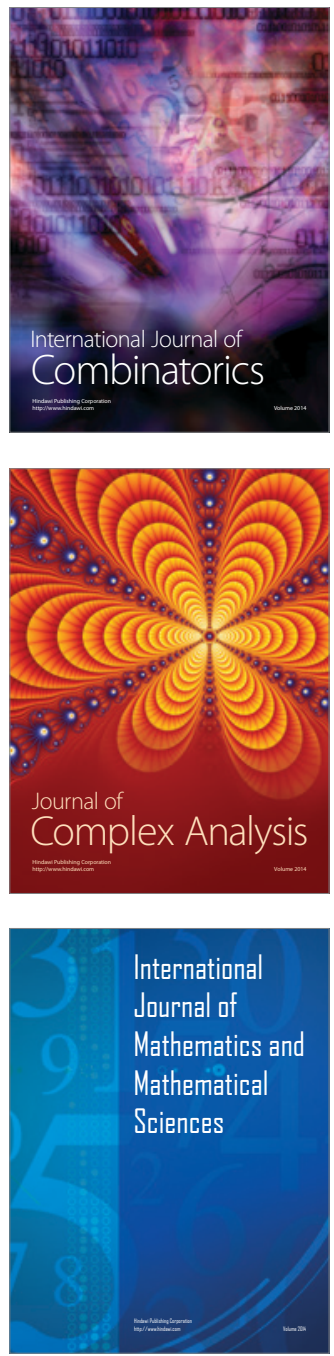
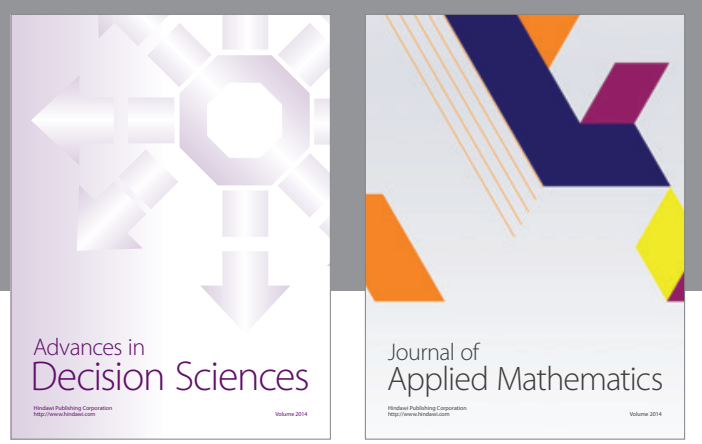

Algebra

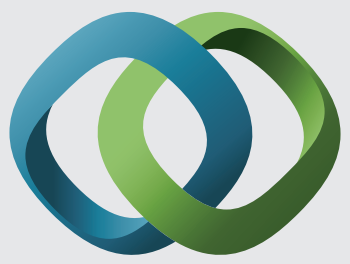

\section{Hindawi}

Submit your manuscripts at

http://www.hindawi.com
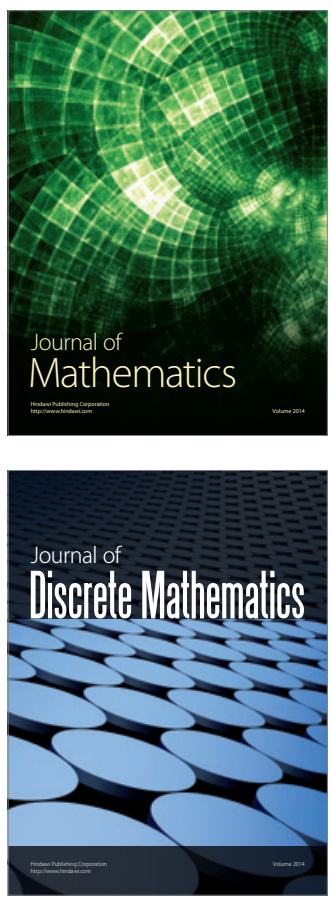

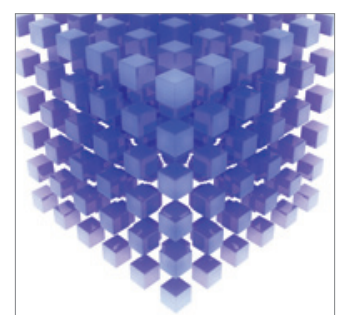

Mathematical Problems in Engineering
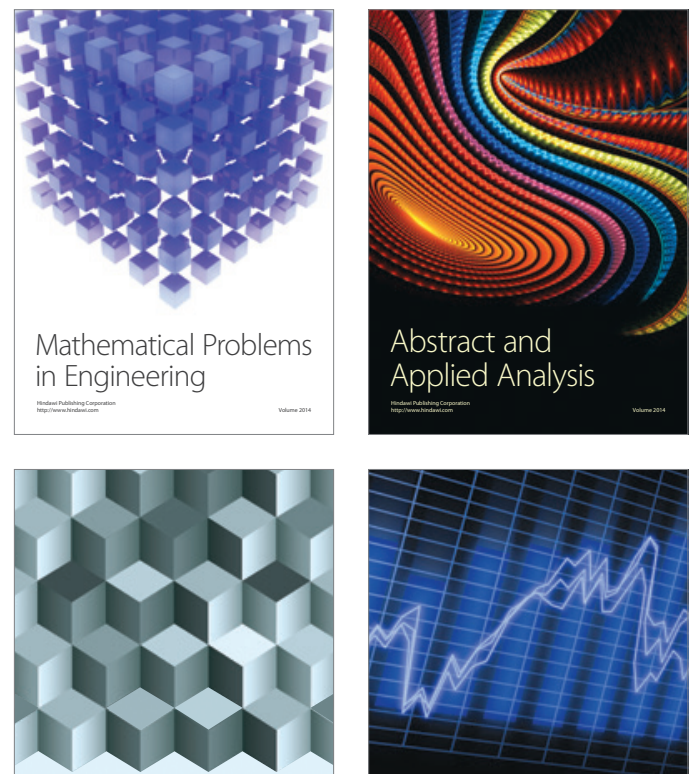

Journal of

Function Spaces

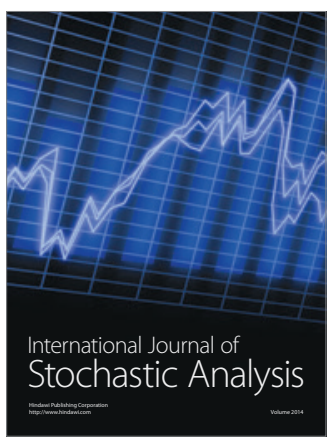

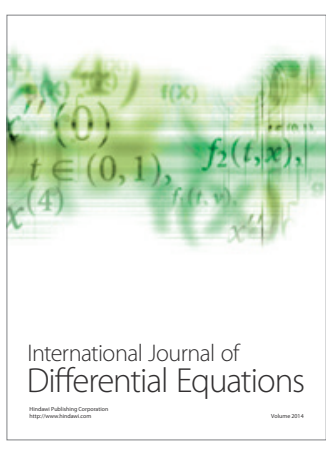
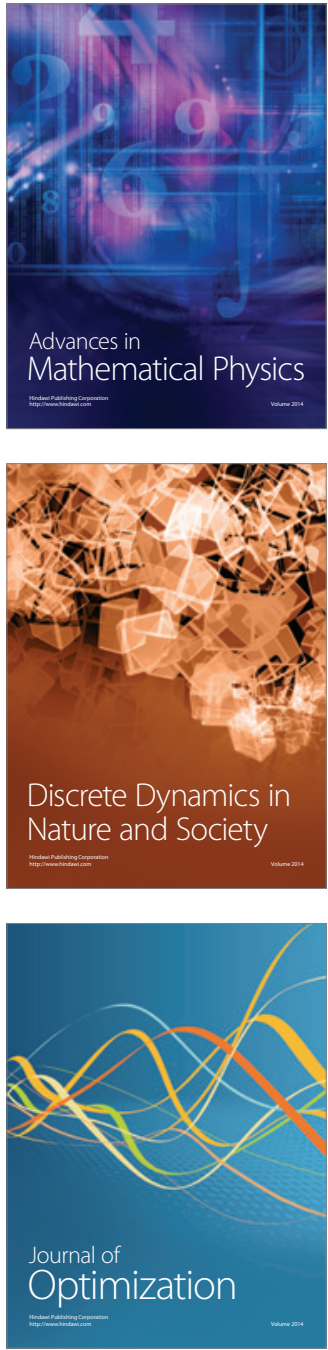